\title{
A cidade vista por cartografias
}

\author{
Maria Júlia Azevedo Gouveia*
}

Tomando como inspiração de trabalho o texto de Ítalo Calvino sobre Ercília ${ }^{1}$ - uma região onde os habitantes constroem cidades estendendo fios coloridos entre as arestas das casas de acordo com as relações (de parentesco, troca, autoridade) entre seus moradores, formando teias de relações intrincadas à procura de uma forma desenvolveram-se trabalhos cartográficos com jovens em suas regiões.

A experiência aqui relatada ocorreu no desenvolvimento do Projeto Jovens Urbanos, iniciativa da fundação Itaú Social, coordenada pelo Cenpec, que conta com o apoio da Secretaria de Assistência Social do Município de São Paulo e de diversas ONGs das regiões de Brasilândia e Capão Redondo.

A cartografia não compreende apenas a elaboração de mapas e não se restringe às marcações visíveis do espaço físico, como na geografia. A psicologia faz uma apropriação desse conceito, ampliando sua abrangência e incorporando a ele uma dimensão subjetiva. Imprime ao conceito de território uma dimensão existencial, ao mesmo tempo que objetiva sua existência, reconhece as marcas que os espaços concretos fazem na vida dos sujeitos. Portanto, um território é um conjunto de lugares, nos quais as pessoas existem, atuam, convivem com outras pessoas e objetos, produzindo realidades.

Aqui, a cartografia é um instrumento de registro que adentra as dimensões do tempo, da memória, das lembranças, das reminiscências, das experiências, das subjetividades, dos desejos. Ela pretende disparar o diálogo entre o "eu" e o "outro" num exercício de alteridade. Permite explicitar as trajetórias de vida que acumulam experiências, articulam ações e decisões individuais e coletivas e o reconhecimento de encontros.

Encontros acontecem quando se depara com algo, alguém ou algum lugar. Eles podem:

* Maria Julia AzeVedo Gouveia é psicóloga, mestre em Educação e coordenadora da área Educação e Comunidade do CENPEC.
- despertar uma vontade de agir, de construir novas realidades - encontro construtivo;

- não fazer diferença - encontro neutro;

- impedir a ação - encontro destrutivo.

A cartografia é um esforço para dar um sentido a conhecimentos disparatados, como "o remo à cavilha, tentando determinar a medida do poder de cada um, mesmo que saibamos que estamos viajando em direção ao mesmo destino". ${ }^{2}$

\section{Formação de jovens cartógrafos em São Paulo}

A formação não acontece fora dos territórios e sim nos lugares em que se viveu, experimentou-se - nos lugares em que se vive hoje, experimenta-se, atua-se e, também, nos lugares que se deseja criar.

A proposta de formação de jovens cartógrafos considera o processo de vida e de desenvolvimento, identificando elementos que, ao longo da vida, puderam ou não potencializar a formação e o desenvolvimento de suas capacidades.

Os grupos de jovens participantes são moradores das subprefeituras de Brasilândia e de Campo Limpo, localizadas, respectivamente, nos extremos das zonas Norte e Sul do Município de São Paulo. Considerando sua condição precária, periférica e com alto grau de vulnerabilidades sociais, esses lugares são tidos como territórios de alto risco e intensa violência urbana.

No senso comum, essas áreas são percebidas como os lugares da pobreza, da moradia popular, da falta de empregos, das demandas por creches, escolas, hospitais, áreas de lazer, equipamentos culturais, dentre outros serviços urbanos.

Do ponto de vista das políticas urbanas, essas áreas são vistas como lugares informais, criados à margem da legislação urbanística, na irregularidade e na clandestinidade.

Da ótica das políticas sociais, essas áreas são encaradas como lugares destituídos dos direitos sociais básicos. 
Todas essas avaliações sobre esses lugares da periferia paulistana são verdadeiras. Entretanto, em meio a essa precariedade territorial, vulnerabilidade social e riscos ambientais, milhões de pessoas vivem. Trata-se de uma multidão metropolitana. Essas pessoas criam relações sociais, entrelaçam solidariedades, organizam coletividades envolvidas em lutas políticas, reivindicam melhores condições de vida, articulam e transformam espaços, constroem histórias e fazem geografias. Essa realidade dinâmica, constantemente atravessada por forças coletivas intensas, indica as potencialidades dessas pessoas nesses locais.

Portanto, os territórios de risco, de alta vulnerabilidade e de profundas exclusões sociais da Brasilândia e do Campo Limpo, como vários outros da imensa periferia da metrópole paulistana, não se constituem somente de fragilidades, carências, pontos fracos. Existem neles também pontos fortes, resistentes, capazes de desenvolver processos altamente inteligentes e com grande ressonância criativa.

É urgente reconhecer as potencialidades imanentes às trajetórias e territórios de todos que buscam utilizar suas capacidades para o desenvolvimento humano (ou desenvolver plenamente suas capacidades). Ou seja, reconhecer potencialidades para ativá-las em processos de formação política e de construção coletiva de conhecimentos sobre as realidades locais, procurando enfrentar as transformações em curso.

Para isso, são realizadas atividades em grupo cuja matéria-prima são os patrimônios existenciais que todos possuem, compostos por:

experiências, memórias, conhecimentos,

imaginação, narrativas, aprendizagens,

valores, sentimentos, emoções,

expectativas, motivações, desejos,

visões, ações, decisões, escolhas e

territórios dos jovens participantes.

Nas atividades, procura-se mostrar uma pequena parte desse patrimônio, a partir de:

diagramas, palavras, diálogos,

enunciados, discursos, sinais,

mapas, esquemas, desenhos,

colagens, dentre outros recursos.

Esse conjunto compõe a investigação cartográfica.

O princípio orientador dessa proposta é constituído por uma forte convicção de que os territórios que estão presentes, mesmo como lembranças, nas trajetórias de vida dos indivíduos e dos grupos sociais são elementos ativos que compõem os processos de formação e autocriação dos jovens, que agenciam esses elementos na busca da construção de sentidos para as próprias experiências.

Os sentidos não são dados, não são preexistentes, aguardando simplesmente serem descobertos, como em uma revelação. Eles são agenciados nos esforços feitos para ativar os elementos encontrados nas trajetórias, nas paisagens, nas vizinhanças.

\section{A investigação cartográfica em ato}

\section{Tempo e memória}

A primeira linha da investigação cartográfica é a cartografia do tempo e da memória. A proposta é cartografar o tempo da memória, o tempo da lembrança, é identificar um momento específico de uma trajetória de vida individual e coletiva.

\section{MEMóRIAS no CAPÃo Redondo}

Nós moramos no Capão Redondo. Seu Gonçalo, avô do Diego, conta que Capão é um lugar onde antigamente as pessoas cuidavam das galinhas e galos para depois venderem os ovos e os animais.

Redondo, porque esse lugar é extenso e redondo. Dizem que o Capão era uma fazenda na qual havia um bosque que, visto de cima, era redondo, e bosque, mato, é o mesmo que capão, então ficou Capão Redondo.

\section{MEMóRIAS NA BRASILÂNDIA}

Quantos se lembram do barro que amassaram na Rua Parapuã para chegar até Itaberaba?

Até 1954, não havia asfalto e, para chegar até lá, o negócio era levar um par de sapatos limpos numa sacola e, ao chegar, trocá-lo pelo outro, sujo, que ainda estava no pé.

Aos sábados e domingos, em frente ao Bar do Gatto, colocava-se um imenso lençol branco e projetavam-se filmes ao ar livre.

Na Rua Parapuã, altura do número 1703, num galpão de madeira, construído pela colônia japonesa, funcionava o primeiro Cine Brasilândia. Existiu um fato que ninguém esquece: as tábuas do banheiro das mulheres tinham mais furos do que "queijo em festa de ratos". 0 incrivel é que havia mais gente disputando esses furos do que dentro do cinema. 


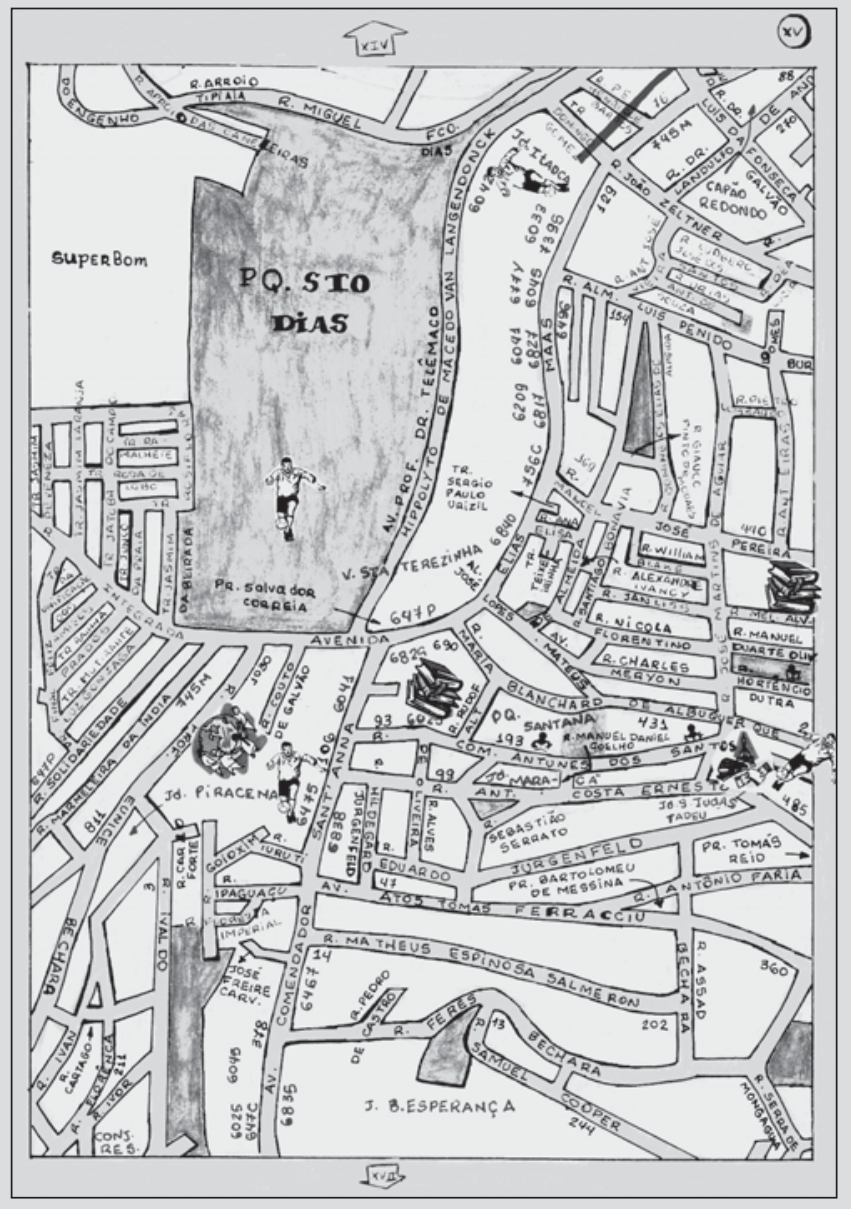

\section{Espaço de agora}

A segunda linha é a cartografia do território atual, os territórios dos dias de hoje, os espaços. Pedaços da cidade que a gente usa para trabalhar, estudar, se divertir, usufruir.

\section{Hoje, no CAPÃo REdondo.}

Encontramos pessoas que lutam para sobreviver, que trabalham o dia inteiro e, à noite, ainda estudam para sair do subemprego, obter uma vida mais saudável, sustentar a familia e the oferecer benefícios, como: escola, vestimentas, calçados, alimentos, lazer e muitos outros.

Capão Redondo é como coração de mãe, sempre cabe mais um desfavorecido pela vida. Podemos oferecer vários adjetivos e cores, como: negro, branco, pardo, das pessoas; cinza e laranja das paredes mal-acabadas das casas. A cor cinza do asfalto esburacado, o amarelo e o marrom dos buracos das madeiras dos barracos; 0

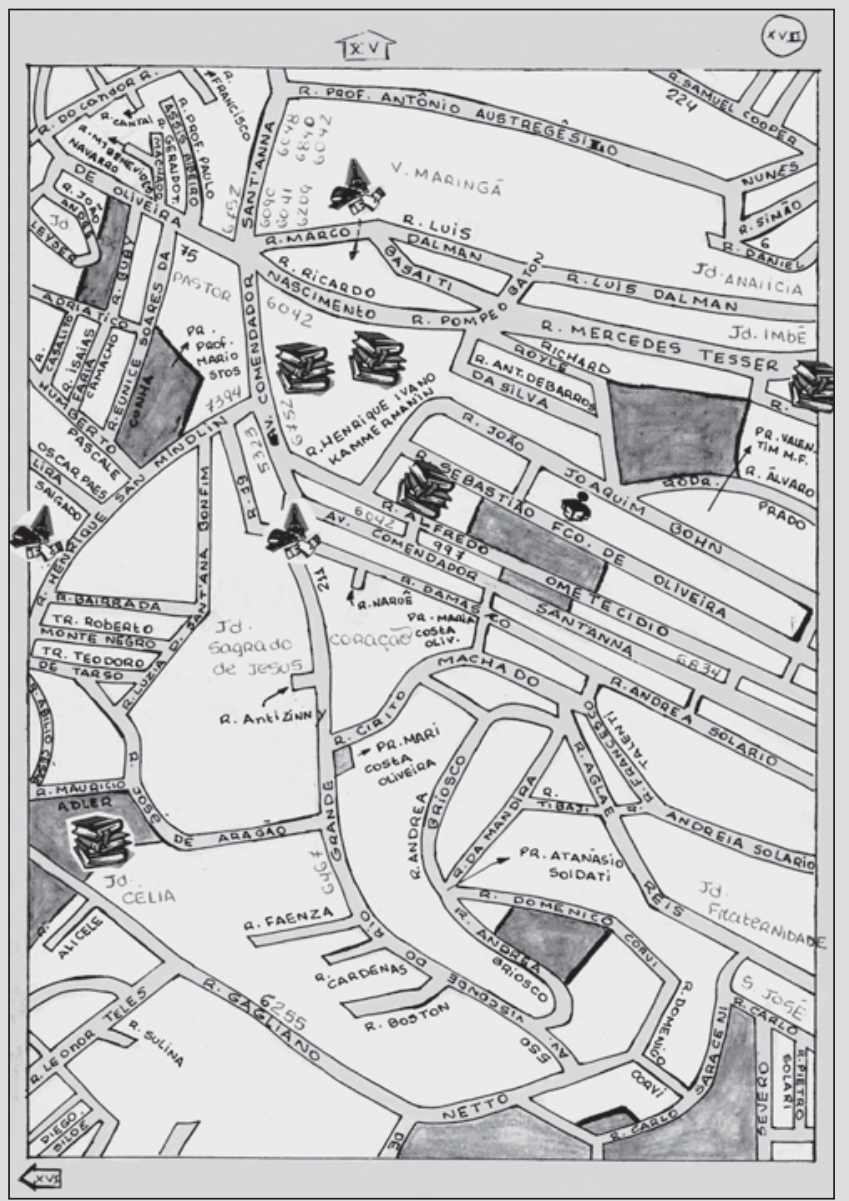

laranja dos tijolos das casas não rebocadas, o vermelho do sangue daqueles que aqui se vão e uma gota esverdeada, que é o símbolo representando a quase morta esperança dos habitantes "menos mau".

As pessoas acham que a Zona Sul é uma região muito perigosa, mas onde, no Brasil, não é perigoso hoje em dia? A periferia é um lugar que pode melhorar muito. É só ter o interesse da sociedade. Eu adoro a região onde moro, é onde eu estudo, me divirto e vou ao Centro Cultural.

\section{HoJe, NA BRAsilÂndia.}

$\mathrm{Na}$ Brasilândia, foram identificados, como lugares de encontro, praças, campinhos de futebol de várzea, escolas públicas, associações de moradores, centros culturais, infocentros, igrejas, delegacia da mulher, Centro Educacional Unificado (CEU) e organizações que realizam trabalhos comunitários. 


\section{0 desejo}

A terceira linha é a cartografia do que se deseja, do que é importante para que seja possível se ter uma mudança nas trajetórias de vida, nas trajetórias da cidade. 0 que é importante realizar para que se possa transformar a realidade.

\section{Moradores sofridos da periferia Sonhar em ser alguém na sociedade Viver em abundância \\ Ver reconhecida a capacidade nossa: Um povo batalhador Fé em Nosso Senhor Noites frias e caladas Pelo som da madrugada \\ É! E a vida? A vida pára. O futuro está em nós \\ Periferia sem problema \\ Jovem urbano é nossa casa. \\ Atitude é nosso lema.}

Jovens do Capão Redondo

A identificação de elementos ao longo da vida das comunidades pôde potencializar o desenvolvimento dos jovens e permitir a realização de suas capacidades por meio de projetos de intervenção em seus territórios.

\section{O amanhã no Capão Redondo}

\section{Projeto “RÁdio Busão"}

- Oque é:

Rádio Biblioteca Móvel (itinerante).

- Como surgiu a idéia:

O grupo de jovens identificou um grande repertório de produção cultural no bairro e ricas narrativas sobre a história local. Por outro lado, constatou-se a falta de espaço para a expressão desse repertório. Os jovens estão estabelecendo parcerias para a aquisição de um ônibus (ou tendas) adaptado para a instalação da rádio e da biblioteca. A programação da rádio privilegiará os artistas locais e a biblioteca incluirá, em seu acervo, registros da memória da região, a partir de narrativas dos moradores.

\section{Projeto SOHAB}

- O que é: Produção e instalação de aquecedores solares resi- denciais de baixo custo e ecologicamente corretos.

- Como surgiu a idéia:

Após a visita à ONG Sociedade do Sol, sediada no Departamento de Física da USP - momento em que conheceram a tecnologia de captação de energia solar - os jovens tiveram a idéia de contribuir com as famílias de sua comunidade que consomem grande parte de seu orçamento no pagamento de contas de energia elétrica. Dessa forma, decidiram aproveitar a energia natural em substituição à energia elétrica, obtendo impacto positivo no orçamento das famílias.

\section{O AMANHÃ NA BRASILÂNDIA}

\section{Projetos Arte no Beco e Novo Olhar}

- Oque é:

Revitalização do espaço público com pintura de fachadas de residências.

- Como surgiu a idéia:

A idéia surgiu da necessidade de criar um local para as crianças brincarem tranqüilas e com mais segurança, para os adultos conviverem com mais comodidade e os idosos andarem por caminhos mais seguros. A proposta é revitalizar locais estratégicos mais precários, estimular a conscientização da preservação de tais espaços e promover melhorias estéticas no bairro, buscando o bem-estar e a valorização da comunidade.

\section{Projeto Cinema Móvel}

- O que é:

Exibição de filmes em espaços públicos da comunidade.

- Como surgiu a idéia:

Os jovens fizeram uma pesquisa na comunidade e os resultados mostraram que $80 \%$ dos moradores nunca tinham ido ao cinema. Assim, a criação de uma estrutura de cinema móvel visa divulgar informações e promover momentos de lazer e cultura para a comunidade.

Esse foi o terceiro momento da proposta, por meio da qual os jovens puderam cartografar um desejo e fazer dele um desejo da cidade.

\section{Notas}

1 Ercília é uma cidade imaginária descrita por Italo Calvino em seu livro Cidades Invisiveis, Biblioteca Folha de S.Paulo, SP, 2003.

2 COWAN, James. O sonho do cartógrafo. São Paulo: Rocco, 1990. 


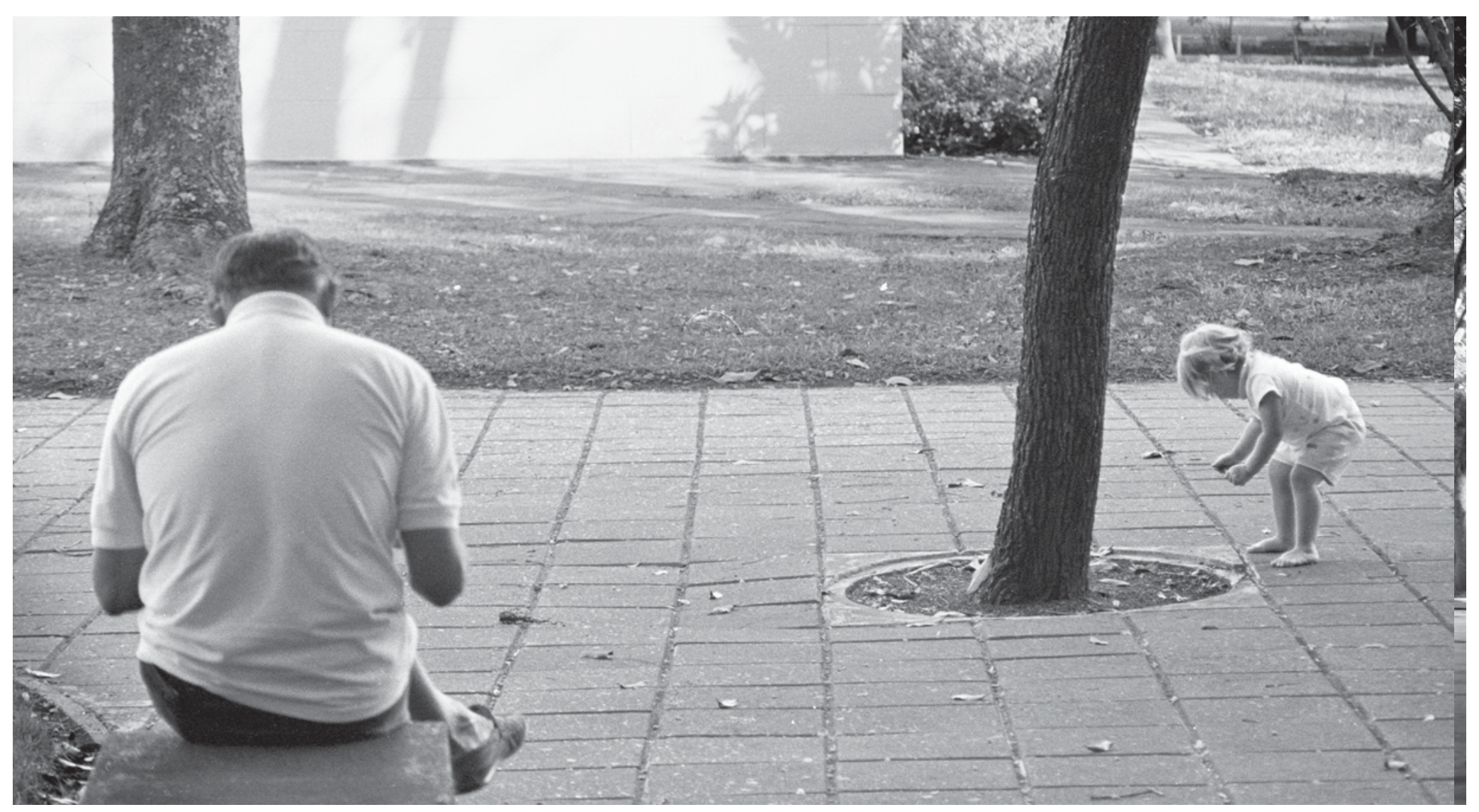

